SCIENTIFIC REPORT

\title{
Macular pigment levels following successful macular hole surgery
}

\author{
K Neelam, N O'Gorman, J Nolan, O O'Donovan, K G Au Eong, S Beatty
}

Br J Ophthalmol 2005;89:1 105-1108. doi: 10.1136/bjo.2004.063834

\begin{abstract}
Aim: Macular pigment (MP) is composed of two hydroxycarotenoids contained within the photoreceptors and the axons of the central neurosensory retina, with peak concentrations in the Henle layer. A full thickness macular hole (FTMH) is characterised by absence of all retinal layers in an area centred at the former centre of the fovea. The authors report the results of a study designed to investigate MP levels in patients following successful FTMH surgery, using Raman spectroscopy, and to correlate these findings with functional and topographic outcomes.

Methods: The following details were recorded for 12 eyes of 12 patients following successful closure of a FTMH: best corrected visual acuity; macula threshold test, fixation, fundus photography, and macular pigment levels using Raman spectroscopy. High resolution imaging of the retina using optical coherence tomography (OCT) was performed in nine of the 12 study eyes.

Results: Mean (SD) best corrected visual acuity was 0.6 (0.4) and improved significantly from preoperative levels. On macula threshold testing of the operated eye, a central scotoma was detectable in one eye only (8.3\%). MP levels were demonstrable in 10 of the 12 study eyes following successful FTMH surgery. MP levels were higher in three study eyes, and lower in seven study eyes, when compared with the fellow eye. Of the three pairs of eyes where MP levels were greater in the study eye, macular pathology was present in two fellow eyes.

Conclusions: The presence of MP was confirmed in the neurosensory retina of an anatomically closed FTMH in 10 of 12 study eyes, although the levels were lower than the fellow normal macula in nine of 10 cases. This suggests a good degree of physiological recovery of photoreceptors and their axons following successful FTMH surgery.
\end{abstract}

A $\mathrm{t}$ the macula, there exists a yellow pigment, known as macular pigment (MP), which is composed of two hydroxycarotenoids, lutein (L) and zeaxanthin (Z). ${ }^{1}$ Evidence is accumulating that this pigment is important for maintenance of macular health through its absorptive and/or its antioxidant properties. ${ }^{23}$

A full thickness macular hole (FTMH) is characterised by absence of all layers of the neurosensory retina at the anatomical fovea, and is an important cause of unilateral visual impairment in the elderly. The vast majority of FTMHs are idiopathic in nature, and typically evolve over a period of weeks to months through a series of stages, described eloquently by Gass. ${ }^{4} 5$

Successful FTMH surgery achieves anatomical closure, and foveal reapposition, with consequential visual improvement. It also suggests physiological and functional recovery of the photoreceptors. However, re-accumulation of MP following successful FTMH surgery has not, to date, been investigated. The ability of the photoreceptors to capture and stabilise $\mathrm{L}$ and $\mathrm{Z}$ following successful FTMH surgery would indicate a good degree of physiological recovery and may reflect functional outcome.

\section{PATIENTS AND METHODS}

This study comprised 12 eyes of 12 patients with successful closure of idiopathic FTMH following standard three port pars plana vitrectomy and intraocular gas tamponade. Informed consent was obtained from each volunteer, and the tenets of the Declaration of Helsinki were adhered to.

Anatomical success was clinically recognised as apposition of the edges of a FTMH, and absence of subretinal fluid cuff. Visual success was defined as an improvement of two or more Snellen lines of best corrected visual acuity.

\section{Assessment of fixation}

Fixation was evaluated as follows. Firstly, a thin slit lamp beam was projected onto the fovea during slit lamp biomicroscopic funduscopy. Then, the patient was asked to fixate the top end of the light beam. Fixation was deemed foveal if the fovea and the superior extremity of the slit lamp beam, as judged by the observer, coincided.

\section{Fundus photography}

A high quality 50 degree colour fundus photograph of the macula was obtained in all subjects postoperatively, using Topcon fundus camera.

\section{Macula threshold test}

A Humphrey visual field analyser, with full threshold strategy, was used to test the macular visual field. Sixteen points, four in each quadrant of the central visual field (within 5 degrees of fixation) were tested.

\section{Measurement protocol for resonance Raman spectroscopy}

We used resonance Raman scattering spectroscopy, a novel, non-invasive, and objective method employing laser technology, to measure MP levels. ${ }^{6}$

\section{Optical coherence tomography (OCT)}

OCT was used to achieve high resolution cross sectional views of the macular region. We used OCT model 2010 (Zeiss Humphrey System), with axial and transverse resolutions of 10-20 $\mu \mathrm{m}$ and $20 \mu \mathrm{m}$, respectively.

\section{RESULTS}

The mean age (SD) of the 12 patients was 67.3 (4.0) years, with a range of $61-75$ years, and the male:female ratio was

Abbreviations: FTMH, full thickness macular hole; $\mathrm{MH}$, macular hole; MP, macular pigment; OCT, optical coherence tomography; RPE, retinal pigment epithelium 

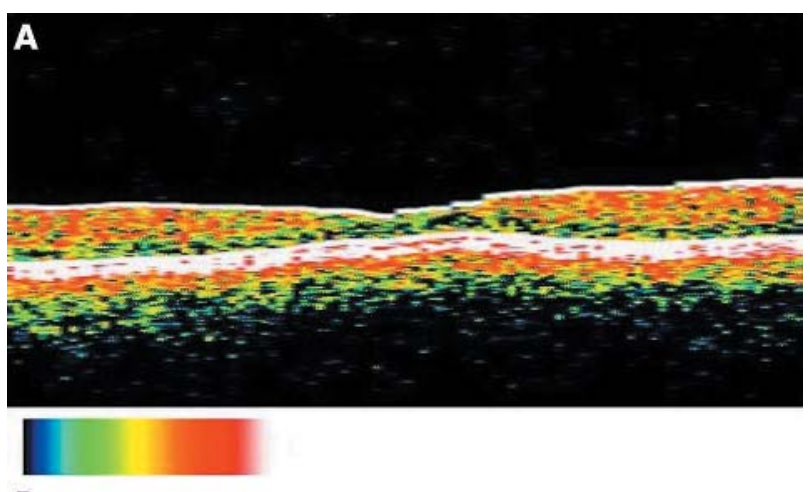

\section{B}

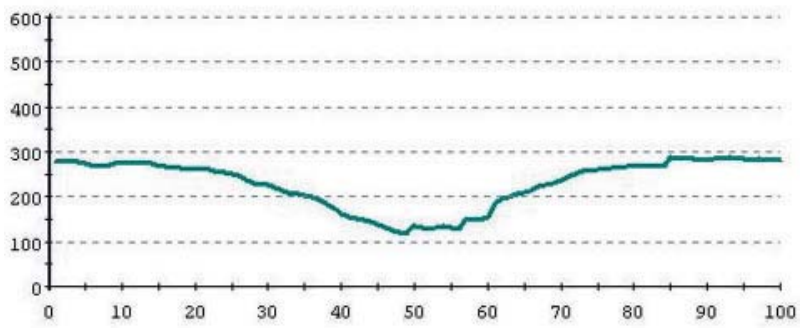

c

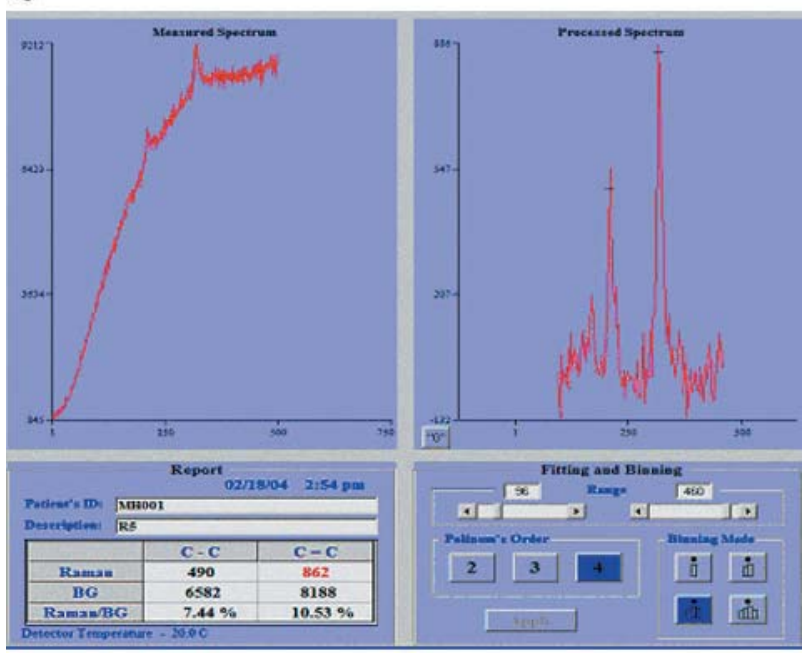

Figure 1 Characteristics of patient with maximum levels of macular pigment. (A) OCT scan; (B) foveal thickness $(\mu \mathrm{m})$; (C) Raman spectrum.

5:7. Eight macular holes $(66.6 \%)$ were classed as stage IV, and the remainder (four, $33.3 \%$ ) as stage III. ${ }^{45}$ The mean preoperative best corrected visual acuity ( $\log M A R)$ was 1.0 (0.3), and ranged from 1.7 to 0.4 .

A postoperative visual improvement of two Snellen lines was observed in eight eyes, and at least one Snellen line improvement was seen in 11 eyes. Following surgery, the presence of co-existing and/or consequential ocular pathology, including cataract, posterior capsule opacification and retinal pigment epithelial (RPE) alterations, compromised the final visual outcome in six $(50 \%)$ patients.

Foveal fixation was demonstrable in 11 of 12 study eyes. There was no evidence of a central scotoma on macula threshold testing, in 10 of 11 study eyes (not available for one study eye). One eye in which fixation could not be demonstrated, but did exhibit a central scotoma, showed evidence of a discrete area of chorioretinal atrophy centred at the fovea. The retinal threshold of a study eye was found to be reduced in three cases, and comparable in five cases, when compared with the fellow healthy eye. In the remaining study
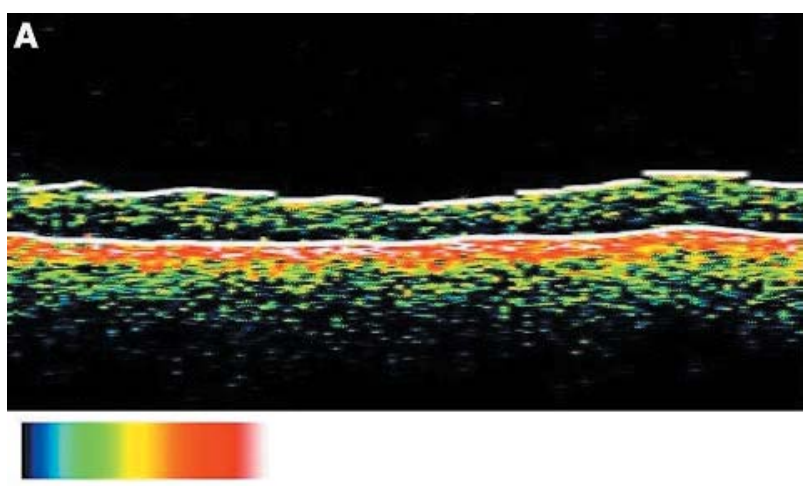

\section{B}
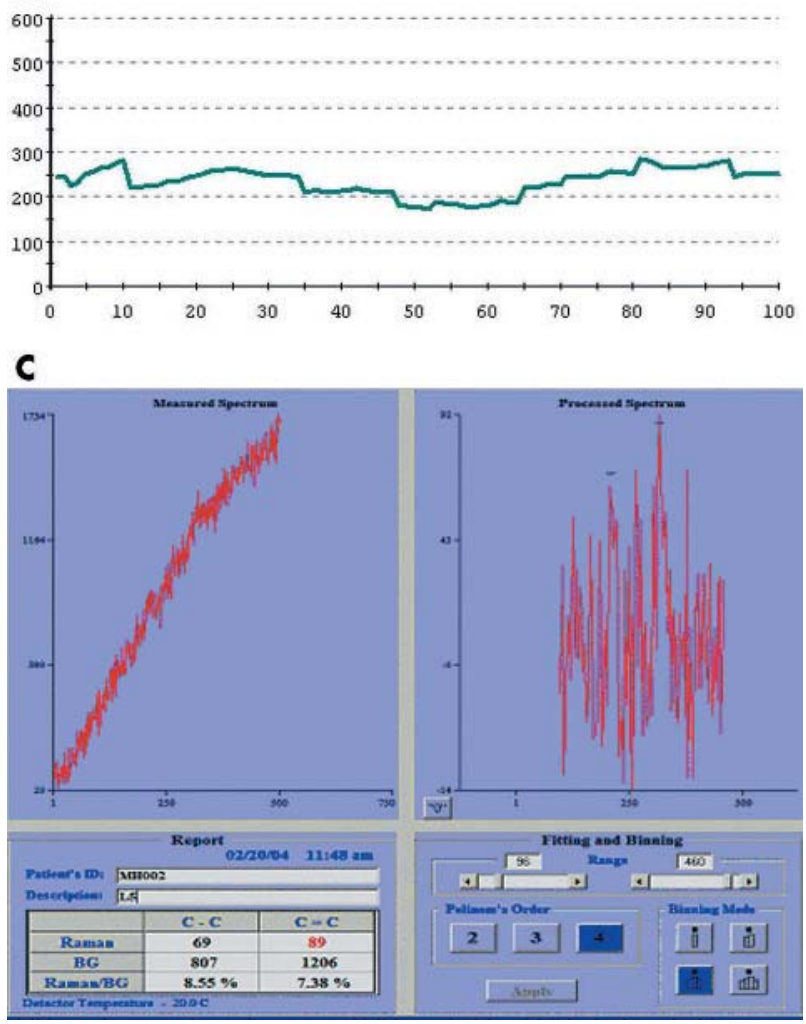

Figure 2 Characteristics of patient with minimum levels of macular pigment. (A) OCT scan; (B) foveal thickness $(\mu \mathrm{m})$; (C) Raman spectrum.

eyes, comparison with its fellow could not be made because of the presence of an untreated FTMH (one) in a fellow eye, and glaucoma related focal field defects (one) in a study eye.

The nine study eyes where OCT imaging was performed demonstrated type I closure (reapproximation of the edges of the hole with central foveal thickness greater than $100 \mu \mathrm{m}$ ), and foveal thickness was $>100 \mu \mathrm{m}$ in five of these. RPE

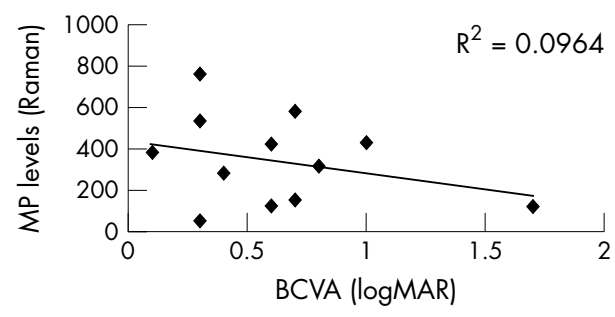

Figure 3 Relation between macular pigment levels and best corrected visual acuity. 


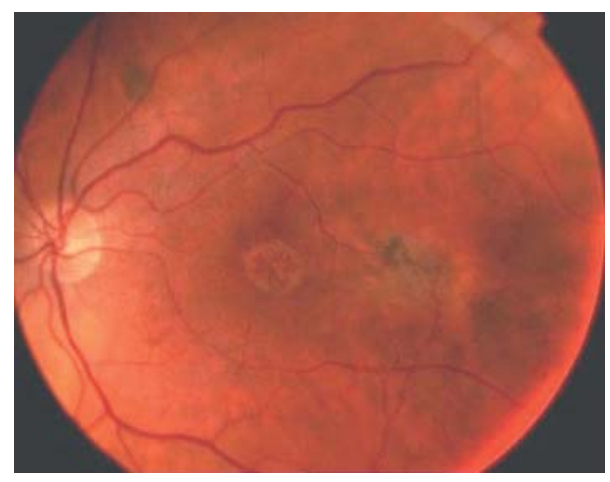

Figure 4 Fundus image of patient with undetectable levels of macular pigment.

alterations were seen at the fovea of two eyes where foveal thickness was $\leqslant 100 \mu \mathrm{m}$. When compared with a fellow healthy macula $(n=8)$, five study eyes exhibited a relatively thinner fovea.

MP was demonstrable in 10 of the 12 study eyes following successful FTMH surgery (mean 348.17 (SD 217.37)), and levels were higher in three (30\%) (fig 1), and lower in seven $(70 \%)$ study eyes when compared with the fellow eye (fig 2 ). MP levels in relation to visual acuity and foveal thickness are given in table 1 , and there was a trend towards a positive relation between visual outcome and MP levels (fig 3). There was no clear relation observed between foveal thickness and MP levels. However, three of the four study eyes with a thin fovea postoperatively $(\leqslant 100 \mu \mathrm{m})$ exhibited less MP than its fellow healthy macula. Of the six study eyes where RPE alterations were seen at the site of the closed FTMH, MP levels were significantly lower than the unaffected fellow eye $(p=0.005)$, but were comparable with the six study eyes where no such alterations were demonstrable $(p=0.825)$. However, in the two study eyes where severe RPE alterations were seen (fig 4), MP levels were very low or undetectable with a maximum reading of 120 .

\section{DISCUSSION}

Our data confirm the presence of MP in 10 of 12 study eyes, suggesting physiological recovery of photoreceptors and their axons following closure of a FTMH. The two study eyes with negligible levels of MP were associated with substantial RPE alterations at the fovea.

Following FTMH surgery, visual recovery depends on the presence of intact and functioning photoreceptors in the area of foveal reapproximation. Indeed, Funata et al have shown that the photoreceptors adjacent to a healed FTMH appear normal on light and electron microscopy, ${ }^{7}$ suggesting maintenance of anatomic integrity of the migrating photoreceptors. However, MP levels depend on uptake by photoreceptors and their axons of dietary carotenoids, and would suggest a good degree of physiological recovery of the neurosensory macula following successful FTMH surgery.

Seven study eyes (58.3\%) exhibited lower levels of MP than its fellow healthy macula, and negligible or undetectable levels of the pigment were demonstrable in another two (16.6\%). Several possible explanations could account for such low levels of MP following successful FTMH surgery. For example, photoreceptor dropout can occur during the genesis of a FTMH, and this would inevitably result in reduced MP levels, even following foveal reapposition, because the pigment is an intracellular compound within the photoreceptors and their axons. Indeed, the concentration of photoreceptors in opercula is inversely related to surgical and functional outcomes following FTMH surgery. ${ }^{8}$

All study eyes demonstrated type I closure of the macular hole, despite being classed as Gass stage III or IV preoperatively. Previous workers have observed substantial variation in the amount of glial proliferation following closure of a macular hole, ${ }^{79}$ and we speculate that greater amounts of such proliferation would be seen following complete closure of a large FTMH. It is unsurprising, therefore, that a relative lack of MP will be seen following closure of stage III and IV macular holes reflecting a parallel relative lack of photoreceptors.

Retinal pigment epithelial alterations were noted in six $(50 \%)$ study eyes following FTMH closure, with a diffuse stippled appearance in five eyes, and a distinct area of chorioretinal atrophy in one eye, consistent with published data. ${ }^{10}$ All eyes with RPE alterations exhibited lower levels of MP than its fellow healthy macula. The physiological functions of photoreceptors depends on a healthy RPE, and it is therefore unsurprising that pathological changes in the RPE are reflected in reduced uptake of the macular carotenoids, with consequential lower MP levels.

Table 1 Clinical characteristics of patients with idiopathic macular hole following successful macular hole surgery

\begin{tabular}{|c|c|c|c|c|c|c|c|c|}
\hline \multirow[b]{2}{*}{$\begin{array}{l}\text { Subject } \\
\text { no }\end{array}$} & \multirow[b]{2}{*}{ Age } & \multirow[b]{2}{*}{ Sex } & \multirow{2}{*}{$\begin{array}{l}\text { Duration of } \\
\text { symptoms } \\
\text { (months) }\end{array}$} & \multirow[b]{2}{*}{ Ocular co-morbidity } & \multirow{2}{*}{$\begin{array}{l}\text { Preoperative } \\
\text { details } \\
\text { Stage of } \\
\text { MH BCVA }\end{array}$} & \multirow{2}{*}{$\begin{array}{l}\text { Postoperative } \\
\text { details } \\
\text { Status of } \\
\text { MH BCVA }\end{array}$} & \multirow{2}{*}{$\begin{array}{l}\text { Foveal } \\
\text { thickness } \\
(\mu \mathrm{m}) \text { with } \\
\text { OCT } \\
\text { MH fellow eye }\end{array}$} & \multirow{2}{*}{$\begin{array}{l}\text { MP levels } \\
\text { MH fellow eye }\end{array}$} \\
\hline & & & & & & & & \\
\hline 1 & 64 & $\mathrm{~F}$ & 5 & No & IV 0.9 & Closed 0.3 & 110120 & 766355 \\
\hline 2 & 68 & $\mathrm{~F}$ & 5 & Increased cup disc ratio (0.5) & IV 1.0 & Closed 0.6 & 180120 & 122302 \\
\hline 3 & 61 & M & Uncertain & $\begin{array}{l}\text { Previous RD surgery, POAG } \\
(\mathrm{L}>\mathrm{R})\end{array}$ & IV 0.9 & Closed 0.7 & 190190 & 153482 \\
\hline 4 & 68 & $M$ & 6 & No & III 1.0 & Closed 0.4 & 100150 & 285404 \\
\hline 5 & 72 & $\mathrm{~F}$ & Uncertain & No & IV 0.4 & Closed 0.1 & $N A^{*} N A^{*}$ & 385139 \\
\hline 6 & 75 & $M$ & 7 & $\begin{array}{l}\text { Retinoschisis (temporal } \\
\text { quadrant) }\end{array}$ & III 0.8 & Closed 0.3 & 100190 & 537569 \\
\hline 7 & 64 & $\mathrm{~F}$ & 7 & Fuchs' endothelial dystrophy & IV 0.8 & Closed 0.7 & 100200 & 587390 \\
\hline 8 & 69 & $\mathrm{~F}$ & 3 & No & IV 1.0 & Closed 0.8 & 170200 & 320773 \\
\hline 9 & 67 & $M$ & Uncertain & No & III 1.7 & Closed 1.0 & 180130 & 433786 \\
\hline 10 & 62 & $\mathrm{~F}$ & 12 & No & IV 1.7 & Closed 1.7 & 20140 & 120350 \\
\hline 11 & 72 & $M$ & Uncertain & No & IV 1.7 & Closed 0.3 & $N^{*}{ }^{*} A^{*}$ & 45387 \\
\hline 12 & 66 & $\mathrm{~F}$ & Uncertain & No & III 1.0 & Closed 0.6 & $N A^{*} \mathrm{NA}^{*}$ & 425634 \\
\hline
\end{tabular}

*NA, OCT not available; MH, macular hole; MP, macular pigment; RD, retinal detachment; POAG, primary open angle glaucoma.

Snellen acuities were converted to logMAR equivalents. 
OCT revealed a thin fovea $(\leqslant 100 \mu \mathrm{m})$ in four of the nine study eyes, comparable with previous studies, ${ }^{11}$ and this may be attributable to a relative reduction in the thickness of the inner retina. Aleman and co-workers have shown that a thin inner retina is associated with a relative lack of MP. ${ }^{12}$ Of the four thin foveas in our series, three exhibited lower levels of MP than its fellow healthy macula.

Three study eyes exhibited higher levels of MP when compared with the fellow macula. Of these, however, two fellow eyes had a macular hole (stage II with epiretinal membrane: $\mathrm{n}=1$; stage IV: $\mathrm{n}=1$ ). In other words, only one study eye ( $11 \%)$ exhibited greater levels of MP (587) than a fellow healthy macula (390).

Clearly, it would be desirable to compare MP levels in the presence of a FTMH with postoperative levels following successful FTMH closure. However, the results of such a study would need to be interpreted with caution because of the documented and variable degree of photoreceptor atrophy adjacent to a hole, ${ }^{13}$ and because of poor fixation preoperatively.

In summary, a demonstrable level of MP exists in the majority of eyes following closure of a full thickness macular hole, although at lower levels than the fellow normal macula. Measurement of MP may provide an alternative approach for assessing the functional outcome in eyes following successful FTMH surgery.

\section{ACKNOWLEDGEMENTS}

The authors would like to acknowledge Professor Philip Cleary at Cork University Hospital, and Mr Alf Whyte of the Ophthalmic Imaging Department, Cork University Hospital for the time and expertise in bringing this paper to fruition.

\section{Authors' affiliations}

K Neelam, N O'Gorman, J Nolan, O O'Donovan, S Beatty, Waterford Institute of Technology, Waterford, Republic of Ireland
K Neelam, S Beatty, Waterford Regional Hospital, Waterford, Republic of Ireland

K G A Eong, Alexandra Hospital, National Healthcare Group, Singapore

Correspondence to: Dr Kumari Neelam, Department of Ophthalmology, Waterford Regional Hospital, Dunmore Road, Waterford, Republic of Ireland; neelamk@sehb.ie

Accepted for publication 29 January 2005

\section{REFERENCES}

1 Bone RA, Landrum JT, Tarsis SL. Preliminary identification of the human macular pigment. Vis Res 1985;25:1531-5.

2 Beatty S, Boulton ME, Henson DB, et al. Macular pigment and age related macular degeneration. Br J Ophthalmol 1999;83:867-77.

3 Landrum JT, Bone RA, Kilburn MD. The macular pigment: a possible role in protection from age-related macular degeneration. Adv Pharm 1997; 38:537-56.

4 Gass JDM. Idiopathic senile macular hole: its early stages and development. Arch Ophthalmol 1988;106:629-39.

5 Gass JDM. Reappraisal of biomicroscopic classification of stages of development of a macular hole. Am J Ophthalmol 1995:119.752-9.

6 Gellermann W, Ermakov IV, Ermakov MR, et al. In vivo resonant Raman measurement of macular carotenoid pigments in the young and the aging human retina. J Opt Soc Am A Opt lmage Sci Vis 2002;19:1 172-86.

7 Funata M, Wendel RT, Green WR, et al. Clinicopathologic study of bilateral macular holes treated with pars plana vitrectomy and gas tamponade. Retina 1992; 12:289-98

8 Ezra E, Munro PMG, Charteris DG. Macular hole opercula. Arch Ophthalmol 1997;115:1381-7.

9 Madreperla SA, Geiger GL, Funata M, et al. Clinicopathologic correlation of a macular hole treated by cortical vitreous peeling and gas tamponade. Ophthalmology 1994;101:682-6.

10 Poliner LS, Tornambe PE. Retinal pigment epitheliopathy after macular hole surgery. Ophthalmology 1992;99:1671-7.

11 Desai VN, Hee MR, Puliafito CA. Optical coherence tomography of macular holes. In: Madreperla SA, McCuen BW, eds. Macular holes: pathogenesis, diagnosis, and Treatment. Boston: Butterworth-Heinemann, 1999:37-47.

12 Aleman TS, Duncan JL, Bieber ML, et al. Macular pigment and lutein supplementation in retinitis pigmentosa and Usher syndrome. Invest Ophthalmol Vis Sci 2001;42:1873-81.

13 Guyer DR, Green WR, De Bustros S, et al. Histopathologic features of idiopathic macular holes and cysts. Ophthalmology 1990;97:1045-51. 